\title{
Uma agenda para a
}

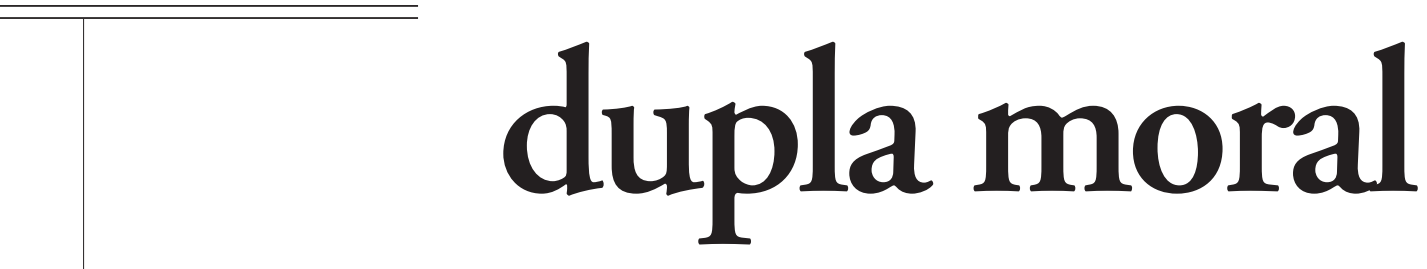

pauta de um recente seminário internacional dedicado à discussão das atuais agendas intelectuais críticas solicitava comunicações a respeito das re-

lações estabelecidas pelos intelectuais com a gestao pública e com os movimentos sociais de seus respectivos países. Nenhuma menção se fazia à questão das relações dos intelectuais com a gestao privada ou, de modo mais amplo e tradicional, das relações dos intelectuais com o setor privado. A ausência desta vertente pelo menos como uma questao pareceu-me notável sobretudo por figurar na pauta do seminário o tema não apenas das agendas intelectuais pessoais como o das agendas institucionais. 
A omissão desse tópico, cuja presença era no entanto automaticamente invocada em negativo, admite uma seqüência de explicações possíveis. Uma, que o tema já havia sido suficientemente estudado e não carecia de maiores abordagens - algo manifestamente equivocado. Outra, que esse não era um assunto digno de ser tratado num seminário acadêmico internacional de respeito. Uma terceira, que as agendas intelectuais críticas, por serem tais, não mantêm e não devem manter relações com o setor privado - esse que, em certos círculos, é o inominável, a encarnação do mal, numa palavra: o inimigo. $\mathrm{O}$ motivo do escamoteamento talvez não deliberado dessa questão será, quem sabe, uma mescla dessas alternativas. De fato, a idéia de que essa questão nem sequer se coloca e, portanto, já está de imediato resolvida, é daquelas que se apresentam como evidentes em inúmeras esferas intelectuais institucionais públicas - a universidade entre elas ou, para pôr as coisas do modo mais correto, a universidade como provavelmente a primeira delas todas. O correlato desse hábito cultural enraizado no Brasil é aquele que tende a excluir, do âmbito da esfera privada e a partir de seu ponto de vista, as relações com as agendas intelectuais críticas, institucionais ou pessoais. O preconceito aqui em jogo ainda tem dupla mão de direção. Existe, é verdade, um Pensamento Nacional das Bases Empresariais que se apresenta como uma agenda intelectual crítica promovida pelos próprios representantes do setor privado. É uma agenda militante por circular dentro e fora de seu meio de origem (faz-se ouvir regularmente por emissoras de rádio, o que significa que se torna uma agenda pública) e não se revela fechada a agendas críticas de outra extração. E instituições de origem privada embora com vocação pública, como o Sesc e o Sesi, incluem rotineiramente, em suas agendas próprias, tópicos das agendas críticas de natureza ou origem pública. Digamos, porém, que o preconceito tem uma dupla mão de direção: do público para o privado e vice-versa.

As relações dos intelectuais ou, melhor, das agendas intelectuais pessoais ou institucionais com a gestão pública no Brasil são inúmeras e freqüentes. E com os movimentos sociais não o são menos. No entanto, em certos setores do meio intelectual brasileiro, em particular no meio das agendas institucionais públicas (que, no caso das agendas críticas, envolvem necessariamente as agendas pessoais), as relações com o setor privado ou a gestão privada mostram-se ainda incipientes, quando não inexistentes. Em certos casos, são mesmo intencionalmente evitadas - um grosso erro histórico neste momento. A universidade pública está entre aqueles redutos intelectuais onde se pratica a minimalização da importância do tema - com sua exclusão das pautas de discussão - e, mesmo, ou principalmente, onde se tenta promover (ou se aceita que se promova) o rompimento deliberado dos canais de interação com o setor privado. Esse rompimento é defendido, se não promovido, quase sempre por uma minoria, ancorada num discurso vastamente débil porém agressivo, nas palavras como nos atos, que mantém o conjunto universitário seqüestrado de uma relação fértil e clara com o setor privado. Até aqui, pode-se dizer que se trata de um jogo político como outros que ocorrem na universidade, embora não por isso mais aceitável. A questão central por trás do fenômeno é que se a maioria universitária se deixa assim sequiestrar é por talvez estar ela mesma, de algum modo, prisioneira dessa mesma concepção na qual por certo não investe todos os seus valores mas que acaba reconhecendo como uma espécie de oposto de um eventual pecado original - o contato com o privado - da qual não se veria isenta e que a faz silenciar-se por receio de ser considerada, exatamente, pecadora.

O rompimento entre o público e o privado promovido por essa agenda pública nãoé total. Procura-se o contato com o setor privado quando há necessidade de aporte de recursos para a manutenção das agendas institucionais e das agendas pessoais transformadas em institucionais ou que destas não se distinguem. O problema para as relações entre ambas as agendas é que não se 
costuma admitir com facilidade que o setor privado possa ter direito de opinião sobre a aplicação desses recursos e, menos ainda, que tenha direito de decisão sobre a própria pauta da agenda institucional antes que ela chegue ao ponto em que é necessária a convocação da participação privada. A situação criada nesta segunda hipótese torna-se mais aguda quando a relação que se procura manter ou que se deveria manter com o setor privado é de tipo perene ou, em todo caso, continuada, não eventual. O contrato que a agenda institucional pública universitária costuma oferecer à agenda privada é o contrato de adesao: o objeto do contrato e as modalidades de sua execução vêm antecipadamente definidos e como tais apresentados ao setor privado pagador, ao qual cabe pegar ou largar. Esse contrato surge eventualmente como aceitável ao setor privado quando seu objeto é um evento individual, isolado, bem determinado. Quando a agenda institucional pública, no entanto, prevê uma ação continuada com a privada, o contrato de adesão revela-se cada vez mais insatisfatório para o setor privado, ele que manifesta o desejo, que lhe parece justificável, de influir nos termos do contrato com sua voz e seu voto. A reação da agenda institucional nesses casos, em particular a universitária, tem sido com freqüência a de recusa: o setor privado pode entrar com os recursos mas não decidir sobre a definição e o desenvolvimento da agenda como um todo, no prazo mais longo. A agenda institucional pública, a universitária sobretudo, costuma considerar este desdobramento benéfico para si mesma, ela que assim demonstra seu senso de oportunidade: consegue recursos e não dá satisfações. Enquanto isso durar, muito bem. Mas pode ser que não dure. E, de todo modo, esse não parece o modo de relacionamento preferível num momento histórico que não é mais aquele de vinte, trinta anos atrás. Sob esse aspecto, a agenda universitária mostra-se estacionada no tempo.

A reação da agenda privada a essa situação pode revelar-se, num prazo nada longo, catastrófica para a agenda pública ao assumir a forma tanto de sua saída do pro- grama da agenda intelectual institucional pública, não raro inviabilizando-a, quanto, inversamente, apresentar-se sob a modalidade da tentativa de controlar de modo exclusivo ou determinante o desenvolvimento e a implementação dessa agenda pública. Exemplo dessa segunda alternativaé a reforma universitária aprovada neste ano de 2001 pelo Conselho de Ministros da Espanha. Entre as metas dessa reforma, apresentada como modo de buscar a melhoria da qualidade do sistema universitário, comparecem o aumento da mobilidade docente, a potencialização da investigação, o apoio ao mérito individual frente à endogamia e o afinamento da gestao. Uma das medidas previstas para alcançar este último item é a mudança na estrutura do Conselho Social da universidade, órgão de participação social encarregado do controle econômico. Esse Conselho passará a compor-se apenas de membros nao universitários (empresas, sindicatos, intelectuais, etc.), com exceção do reitor, do secretário-geral e do gerente. Esta proposição, que pode ou não ser ratificada mas que em todo caso já está formulada e aponta claramente para uma tendência, configura mesmo um caso de reação extrema da agenda privada e da moral privada (ou da sociedade como um todo), bem como da própria agenda pública maior representada pelo governo central, ao fechamento da agenda universitária sobre si mesma e à sua pouca receptividade à voz e ao voto não-universitários, coisa que na Espanha parece, assim, tão acentuada quanto no Brasil. Quando se nota que os demais instrumentos da reforma universitária espanhola visam conseguir mais mobilidade docente e menos endogamia, percebe-se que o diagnóstico feito pelo governo espanhol efetivamente detectou ou entende ter detectado o fechamento da agenda universitária sobre si mesma pelo menos no que diz respeito ao modo de controle da máquina universitária e às respostas que deveria fornecer à sociedade. Esse fechamento pode ser de natureza ideológica ou fruto de um mero comportamento oportunístico e corporativista desejoso de manter a sociedade exterior, que 
É fato que, pelo menos até o momento em que consigam de senvolver com plena autonomia suas próprias agendas intelectuais lo que significa que terão formado seu próprio quadro de recursos humanos nessa área - algo tanto mais fáci quanto se multiplicam por uma multidão cada vez mais intelectualizada as fontes de acesso à informação e se retrai o monopólio do conhecimento antes exercido pela unversidade, tanto a pública como a privada), as entidades do setor privado que assim comecam a agir precisam manter relações com agenda intelectuais pessoais ou institucionais públicas. Mas não será necessário que seja sempre assim ou que seja as sim por muito mais tempo. Mais ainda, determinadas agendas intelectuais públicas até aqui autônomas (ou assim consideradas) correm o risco de serem sufocadas, como parece apontar o caso da Espanha, ou mesmo, de desaparecer. E ne cessário ainda, admitir como possibilidade teórica que as agendas privadas poderão vi a realizar com igual grau de autonomia crítica o mesmo programa que antes certas agendas públicas, como a da universidade, encarregavamse de aplicar. $O$ que isso poderá acarretar é o aniquilamento gradativo e o eventual desaparecimento /ou confinamento à irrelevância) das agendas públicas tais como hoje conhecidas. Isso pode ser um mal pode ser um bem; certamente será uma outra coisa, diversa daquela hoje existente, e cujo impacto final ainda não está claro. paga pela universidade, longe das alavancas de controle das ações e projetos universitários. Uma coisa ou outra, o governo espanhol faz um diagnóstico que, por mais que se inscreva no quadro de um confronto político maior (envolvendo por exemplo uma concepção estreita das obrigações do Estado para com a universidade em tempos de neoliberalismo), para os que conhecem por pouco que seja o modo organizacional universitário dificilmente poderá ser tachado de falso. Extremado talvez; falso, não.

Outra forma que pode assumir a reação da agenda privada à insuficiência ou inadequação das relações com as agendas intelectuais institucionais públicas já se verifica no Brasil, onde o setor privado acelera a implementação de suas próprias agendas intelectuais (que talvez nem sempre sejam críticas, mas que nem por isso deixam de ser intelectuais), não apenas do ponto de vista programático (escolha do que promover) como também de sua implementação física concreta (executar o que foi decidido). Exemplo é a proliferação de centros culturais, de informação mas também de formação e pesquisa, mantidos pela iniciativa privada, que desse modo deixa de apoiar as agendas intelectuais autônomas institucionais, públicas na sua origem e sua destinação - assim como são inegavelmente públicas na sua destinação, se não na origem, as iniciativas do setor privado a que me refiro (há uma tendência para considerar necessariamente autônomas pelo menos algumas das agendas intelectuais, como as universitárias, mas isso é menos uma evidência do que objeto de comprovação a efetivar-se). Essas iniciativas são sem dúvida facilitadas pela atual legislação de incentivos fiscais que torna possível e preferível para o setor privado, sob o pretexto nem sempre falso da ineficácia das agendas públicas ou da dificuldade no relacionamento com elas, desenvolver, com recursos no entanto públicos, suas próprias agendas em seu próprio nome. O que a agenda privada ganha com isso é maior visibilidade social e rapidez na consecução dos objetivos corporativos dependentes da disseminação e aceitação de sua imagem.
Mesmo assim facilitadas pela legislação, essas iniciativas ligam-se, entre outras coisas, vale insistir, à dificuldade no relacionamento entre a agenda privada e as agendas intelectuais institucionais públicas. As instituições públicas que têm de recorrer à iniciativa privada para manter suas agendas, inclusive as básicas, conhecem as queixas consistentes desse setor no que diz respeito à dificuldade de definir com o setor público um programa ágil, satisfatório para ambas as partes e com garantia de continuidade, coisa que a instituição pública quase sempre está longe de poder garantir. Entre os motivos para o desapontamento do setor privado está a dificuldade ou impossibilidade de associar seu nome, na proporção que lhe parece justa, à iniciativa pela qual paga (1). A gestão pública comporta-se, nesse caso, como se a proximidade do nome privado automaticamente, e por esse simples fato, pudesse denegrir o nome público. A idéia de que essa associação é sempre suspeita de ocultar transações ilícitas ou de visar o benefício da agenda primária é primária demais para contar como argumento, embora assim funcione. Mas por trás dessa recusa de combinar a ação pública com a privada existe, outras vezes, como se observa em círculos puristas no interior da universidade, uma visão de mundo mais elaborada porém não menos elementar. $\mathrm{O}$ que se tem aqui é uma representação de todo enviesada, para dizer o mínimo, da produtividade social, encarada como se pudesse ser decomposta em duas partes estanques sem comunicação direta entre si - uma representação nitidamente ideológica, fragmentada e fragmentante, que constitui a origem de uma dupla moral freqüentemente imobilizante e cujo resultado final tem sido o beneficiamento daquele setor mesmo que esse entendimento pretende rejeitar. E não apenas a produtividade social é vista como incomunicável em seus dois segmentos, numa concepção fantasista de mundo, como se vê a produtividade pública, se isso pode existir em si, como a depositária de toda a positividade social. Esse abismo instituído entre o público e o privado constitui um sistema de dupla 
moral cujos dois componentes seriam, nessa representação maniqueísta, inteiramente antitéticos: de um lado, a moral da agenda privada; de outro, a moral da agenda pública.

Esta não é uma especificidade brasileira. A proposta de reforma universitária espanhola repousa, com toda evidência, num sistema análogo de dupla moral baseado na certeza de que a moral do outro é incompatível com a minha e, portanto, está errada. E também nos EUA - onde a eventual excelência do discurso público, ou para o público, em nada oculta seu afastamento por vezes brutal do eixo do mundo real - a dupla moral é um princípio de política contemporânea. O governo de George W. Bush, no mês de agosto de 2001, proibiu a utilização de recursos públicos para as pesquisas com células-tronco, obtidas de embriões humanos de quatro ou cinco dias de idade e que podem transformar-se em qualquer tecido com a propriedade de combater uma lista de doenças hoje incuráveis, entre eles o mal de Alzheimer e diabetes. Proibiu-se, em outras palavras, o uso de recursos públicos na manipulação genética avançada. Os laboratórios privados, porém, estão livres para implementar o programa que pretenderem nessa área (2). Ou em áreas análogas, ou mais ousadas. A moral dupla está aqui também em jogo. Alguns desejarão denominá-la por um outro nome mais claro: hipocrisia. $\mathrm{O}$ ente público, em nome dos entes privados que são todos aqueles que o ente público deve representar e proteger e que o constituem, por uma questão alegadamente moral, abstém-se de fazer algo que os entes privados, que formam o ente público, e por decisão deste, estão livres para fazer. Essa esquizofrenia avançada contamina não só aqueles a quem o presidente americano faz assim uma barretada (os antiaborcionistas, por exemplo) como os que combatem sua decisão dizendo que o setor público deveria ter o mesmo direito e a mesma ou maior responsabilidade nesse campo porque, dizem esses críticos, haveria maior probabilidade de cometeremse coisas eticamente reprováveis no âmbito privado do que no público, submetido a um controle e um rigor maiores. A idéia da dupla moral, e da necessidade dessa dupla moral, continua viva mesmo nessa agenda crítica (supostamente crítica) e é um exemplo da força de um hábito cultural tão enraizado quão desterritorializado. O acúmulo de casos históricos ao longo do século XX - e não apenas em suas primeiras três ou quatro décadas como bem recentementemostra, com exuberância de provas, como o controle ético no setor público não é necessariamente maior que no privado, inclusive no que diz respeito às experimentações científicas ( para não mencionar aquelas, "mais simples", relacionadas com a segurança das pessoas ou com a qualidade da educação que recebem ou deveriam receber). É óbvio, por outro lado, que por trás desse duplo discurso moral do Estado, ou de quem momentaneamente o representa, desponta a intenção, de forma indiscutivelmente assumida por George W. Bush em várias outras ocasiões, de garantir para o setor privado a dianteira num campo sensível da pesquisa científica capaz de gerar lucros de um montante astronômico - dos quais o setor público fica assim desde logo em grande parte, e na maior parte, privado (com todos os sentidos implicados nesse trocadilho inevitável...).

Os envolvidos nesse jogo da dupla moral preferem ignorar a evidência cristalina de que o setor público não detém, nem de longe, o monopólio da virtude assim como o privado não exerce, nem de longe, o da competência ou o da racionalidade. Deveria ser banal dizer que uns e outros são valores disseminados entre os dois setores. A distribuição desses valores entre os dois campos pode não ser eqüitativa e em determinados momentos históricos, assim como em certas atividades e sob certos aspectos, certamente é uma distribuição que se dá segundo padrões irregulares - como não pode deixar de ser pelo menos enquanto uma eventual e ainda imaginária operação de engenharia genética, contornando todos os infinitos azares do aprendizado cultural - circunstancial e histórico - não conseguir dotar todos e cada um dos seres humanos com a mesma quantidade e qualidade de
2 A subseqüente modificação dessa proibição, permitindo re cursos federais apenas para 60 inhagens de células-tronco sob o pretexto de que já existem, não altera a essência da questão 
3 A produtividade social compõese hoje, cada vez mais, por uma miríade de "privados" molecu lares que independem tanto do Estado quanto dos grandes blocos privados ou que deles de pendem apenas indiretamente. Num sistema social onde mprego é sempre mais escasso e substituído pelo trabalho autônomo lindependente do setor público tradicional e dos grandes grupos privados tradcionais), a proliferação dos "pr vados" é uma força considerá vel e inevitável, como o mostra por exemplo, a fragmentação do serviço público dos transportes em São Paulo numa vasta colônia de iniciativas privadas como a dos perueiros. Essa frag mentação pode mesmo repre sentar um avanco social diante do sistema disfuncional sustentado diretamente ora pelo poder público, tocado por indivdualidades burocratizadas sem a menor vocação de servir ao público; ora por um setor privado acomodado num oligopólio consagrado pelo poder público e que, funcionando em economia de escala, não tem interes se algum em zelar pela qualidade do serviço individual prestado a uma multidão de diferenciadas necessidades e desejos de locomoção. A população usuá ria da cidade percebeu de imediato essa vantagem e aderiu ela, colocando desde logo en xeque a lógica do setor privado tradicional e os hábitos culturais do setor público tradicional, qu se vê agora diante do dilema que consiste em conciliar a re gulamentação do uso da via pi blica e da qualidade do serviço com a ampliação das possibildades de trabalho e com um novo modo de produtividad social que revela a inadequação do sistema anterior. A lógica atual da escassez de emprego combinada com a descoberta de que o emprego público não mais a seguranca contra os imprevistos e a miséria que um dia pôde ter sido, apresenta a multiplicação dos privados molecularizados como uma sada a considerar - uma saíd difícil de ser aceita tanto pelo setor privado tradiciona monopolista ou oligopolista como pelo Estado que ainda tem pretensões a exercer o mo nopólio da produtividade socia Icomo em Cuba, que vem reje tando as tentativas molecula rizadas de estabelecimento de atividades econômicas indiv dualizadas). A fragmentação e multiplicação do privado, fenô meno que acompanha a concentração do capital privado orna sempre mais inevitávelle ar em conta a agenda privada - no caso, as agendas privadas valores em embrião dos quais dependem uma moral, qualquer que seja. Até lá, esses valores não se concentram com exclusividade num ou noutro desses dois setores, o público ou o privado, embora não se distribuam de modo igual por um e outro. Mas o hábito cultural impede a visão dessa obviedade. Investigar as causas históricas e os antecedentes desse hábito cultural endurecido e identificar a figura ideológica substituída pelo novo esquematismo proposto pelos adeptos da dupla moral pode requerer mais espaço e investigação do que aqueles aqui cabíveis. Pode, também, pelo contrário, ser uma operação bem simples. De todo modo, mesmo que o interesse imediato seja, aqui, não proceder a essa discussão mas apenas o de desenhar o que está na balança com a continuidade desse jogo moral e o que se pode vislumbrar como saída para um impasse de todo falso, é inevitável perceber que a idéia de uma moral pública a ser privilegiada propõe-se como a nova bandeira que vem substituir a de uma classe social em particular, no caso a operária ou o proletariado, como sujeito privilegiável da história e detentor de todas as positividades. Esta será uma visão mais ampla que a anterior. Mas, assim como aquela primeira configuração está hoje francamente em baixa, do mesmo modo a noção de um programa moral que deteria com exclusividade o poder de operar a grande transformação final a caminho da utopia é algo de todo deslocado na complexidade social do atual mundo ligado em rede.

Dizer que a moral do setor público não tem todas as credenciais supostas por aqueles que a defendem como superior à moral da agenda privada não significa assumir uma posição contrária à idéia de Estado, ele que é rotineiramente associado à noção da moral da agenda pública como seu sustentáculo e promotor mas que não é nem sua condição necessária, nem sua qualidade bastante. Em outras palavras, a moral pública estende-se sobre um campo bem maior que aquele coberto pelo Estado e a este não se restringe. A idéia de que para defender o Estado é preciso sacrificar tudo não apenas não mais se sustenta como de- monstra-se uma idéia francamente assustadora, no limite, hedionda. O Estado não é ou não mais é, tampouco ele, o sujeito privilegiado da história - como não o é nenhuma classe social em particular, ou o setor privado como um todo. É um sujeito importante da história e seu papel como tal deve ser preservado. Não, todavia, como um imperativo absoluto, em qualquer situação e acima de tudo. Isto dito, a relativização da moral da agenda pública, como contrapartida da relativização da moral da agenda privada - operação que consiste em negar, a uma e outra, o monopólio da virtude e o caráter de única alternativa positiva - não implica neutralização do Estado. Significa apenas, em última instância, que no momento atual, provavelmente mais que em outros, a produtividade social resulta do conjunto de forças produtivas do Estado e do setor privado - e, no interior de ambos, dos indivíduos e das classes sociais - e que a produtividade do setor público se dá também em decorrência da ação do setor privado, direta ou indiretamente. Há evidentes desdobramentos desta colocação, como o que diz respeito à adequada distribuição social dos rendimentos dessa produtividade social. Enquanto esse aspecto não é equacionado e resolvido, no entanto, não há por que recusar a idéia do papel da produtividade privada naquela pública e vice-versa. E pela simples razão de que a autoria dessa produtividade é definida e redefinida constantemente segundo a participação real, nela, dos diferentes agentes (3)

Essa redefinição constante da autoria da produtividade social, e portanto da vida social, pelos diferentes indivíduos e grupos sociais (4), torna imprescindível e inevitável tanto o reconhecimento da legitimidade de fazer-se ouvir a voz e o voto do outro como a articulação entre as duas morais que se opõem (5). Talvez a fusão entre elas numa única moral que dê conta do equilíbrio social maior seja inviável a curto prazo. E, talvez, indesejável. O fato é que o setor privado e sua moral não podem ser desentranhados desse processo uma vez que são fundamentais para a vida do siste- 
ma como um todo, num grau que o Estado não pode mais suprir se de repente se descobrir abandonado por esse feixe de forças ou se dele decidir alienar-se por um equivocado desejo próprio. Assim como a moral da agenda pública não pode ser posta de lado, nem como hipótese política, nem como força produtiva concreta.

Um modo, se não de fusão, em todo caso de composição das duas morais começa a surgir na figura jurídica da organização social, que prevê a co-gestão, pelo público e pelo privado, de fundos de produtividade de origem pública (seja ela a produtividade do conhecimento científico, a produtividade artística, a produtividade da saúde ou outra). No estágio atual da produtividade social, e considerando o atual modo de organização social, certas instituições públicas que não reproduzem seu capital de modo direto e imediato em valor econômico tangível - como museus, sinfônicas, hospitais e escolas de todos os graus, inclusive as universidades - em países como o Brasil, e na perspectiva atual, correm o risco de estagnar e, no limite, de desaparecer, comidas pelas bordas, num processo de deterioração gradativa que as reduzirá à inexpressividade ou, no horizonte do provável, pela simples e direta incorporação ao setor privado (ainda que de vocação pública). Essa é uma evidência cada vez mais dura. E como o setor privado reluta sempre mais em financiar certos formatos do setor público sem ter a possibilidade de manifestar-se sobre essa destinação ou, mesmo, de associar-se a eles de modo satisfatório, a organização social surge como forma de compromisso que possibilita atender aos interesses públicos com dificuldades para encontrar apoio no próprio setor público (por motivos meramente econômicos ou outros) e também no setor privado, mantido a distância por uma desfocada moral da agenda pública.

Não é possível fazer ilusões sobre a delicadeza do tema e a facilidade de introdução e implementação de um programa dessa natureza numa agenda pública como a da universidade. Mas não resta dúvida sobre a oportunidade de criar-se desde logo uma agenda para esse tópico. Os motivos para tanto envolvem aqueles de natureza pragmática imediata-de que modo manter adequadamente, hoje, serviços ainda equivocadamente considerados suplementares, como os culturais, e de que modo manter, amanhã, uma agenda inteira como a da universidade pública - e outros de alcance social maior, de natureza quase teleológica, e que dizem respeito à iluminação e encaminhamento de soluções para o dilema representado por essa dupla moral. Colocálas em associação, sem a supressão de uma pela outra, será uma meta audaz e generosa a ser alcançada por uma hipótese política esclarecida. Não será fácil. Mas é algo que se pode perseguir assintoticamente, aproximando-se sempre mais da resolução mesmo que sem nela tocar. A universidade pode dar sua parcela de contribuição para o processo. Tratar o assunto pelos recursos curriculares apropriados, de modo a informar todas as agendas pessoais e institucionais, públicas e privadas, é uma das vias óbvias. Insuficiente, porém. Esta é uma agenda a ser enfrentada desde logo administrativa e politicamente, não apenas curricularmente.

A questão da dupla moral é uma das que pedem esse esforço de múltiplo e constante reenfocamento. Há uma série de perguntas a responder: qual o futuro das relações entre as agendas intelectuais pessoais e institucionais com a agenda ou as agendas privadas? Qual a natureza e as dimensões dessas relações no momento? Como proceder para que as agendas de um e outro setor convirjam? Como despertar as agendas intelectuais críticas em formação para esse tópico? Quais as alternativas disponíveis para a superação da dupla moral? Como inscrever esse tema na agenda da universidade? Se há uma função central para a universidade é a que consiste em detectar e desconstruir os hábitos culturais acomodados, por isso confortáveis. Dito com Wittgenstein, trata-se de pensar sempre de modo diferente. É bem o momento de pensar diferente o tema da dupla moral, um tema longe de dizer respeito apenas à universidade.
4 Esta operação implica aindaé verdade e é inevitável - uma eapropriação dessa produtvidade, como, por exemplo, a reapropriação do saber, socialmente produzido, por indivduos privados que o usarão para seus fins próprios e exclu sivos, como passa a acontecer a partir do momento que USP abre a todos seu portal do conhecimento: e como de fato sempre aconteceu, na univesidade, com a transferência fo mal e certificada, por diplomas, do conhecimento socialmente produzido para indivi duos privados que em seguida - aplicarão para seu desenvolvimento pessoal e privado não raro acima de todas a outras coisas e implicações. A autoria coniunta da produção do conhecimento e a apropria ção privada dessa produtividade por parte dos parceiros na operação, ou por parte pelo menos de um dos parceiros, já é uma prática em determina dos centros universitários. Com o projeto de colocar o estado da Califórnia no centro do desenvolvimento tecnológico de ponta, a Universidade da Califórnia em Los Angeles e a Universidade da Califórnia em Santa Bárbara anunciam a cria ção, neste mês de agosto de 2001, de um instituto de pesquisas que deverá abrigar pesquisadores, professores, estu dantes e cientistas do setor privado. Dos US\$350 milhões necessários, o estado da Califórnia entrará com 100 milhões, o governo federal com 110 milhões, fundações privadas com 90 milhões e um con junto de 20 empresas priva das com 50 milhões. O setor privado entra assim com 140 milhões de um total de 350 menos da metade. E o setor privado se apropriará diretamente, e em larga escala dessa produtividade. Neste caso, porém, o interesse público sobrepõe-se claramente questões localizadas como a da dupla moral: prevalece cálculo de que a prazo médio ou longo, a totalidade da so ciedade se beneficiará com o empreendimento. A fusão da duas morais já se faz aqui.

5 É claro que a voz e o voto do público deve fazer-se ouvir no privado, assim como a voze o voto dos privados molecula rizados que participam da produtividade também devefazese no setor público e no interio do setor privado corporativo Mas a questão aqui, no seto público, é como receber a voz e o voto do privado, corpora tivo ou molecularizado. 